\title{
Comparison of Determinants of Clinical Recovery from Acute Watery Diarrhea of Well-nourished and Malnourished Children in an Urban Hospital
}

\author{
Farzana Haque $^{1 *}$ and Meghnad Bhowmick \\ Institute of Nutrition and Food Science, University of Dhaka ${ }^{1}$
}

\begin{abstract}
:
A hospital based cross sectional study was carried out among the under-five children admitted to the longer stay wards (LSU) of the hospital of ICDDR,B to investigate the relationship between children's nutritional status and clinical recovery as well as sock, economic condition. Nutritional status was determined by anthropometric measurements. The study conducted on 94 children of 6-59 months, of whom 49 were malnourished and 49 were well nourished 64 of them were male and 35 were female. (It means that boy's are more sufferers in diarrhea than girls.) (Children's age come within a range of 6-59) month. Mother's education level was lower, $32.6 \%$ mothers were illiterate and $40 \%$ mothers of malnourished children were illiterate where, $25 \%$ mothers having well nourished child were illiterate. Most of the malnourished children's Family income was below TK. 5,000 per month for majority of the parents whereas, most of the well nourished children's family income was 8,000tk. It shows that, children having low family income are more likely malnourished than well nourished children. Family member was within 4 persons for majority of the well nourished children's households'. On the other hand family member was more than 5 in out of the malnourished households. Within their limited income; it was difficult to maintain a medium size family properly. Our study reveals that knowledge, attitude and practices of dietary pattern, health, sanitation and immunization of the malnourished children's family were lower than well-nourished children's family. Their nutritional knowledge was too low, compared with well nourished children's parents. In our study, Most of the parents of well-nourished children used to feed colostrums (80.6\%) but Parents having malnourished children discarded colostrums (93.6\%). Our study reveals that 64.4\% malnourished children's mother has started complementary food in $<2$ months of age ,on the other hand majority of well-nourished children's mother gave their child complementary food at the age of 6-9 months. It has been seen that, the majority of well nourished children (62\%) were immunized by taking all doses of vaccines. where as most of the malnourished children (49\%) has not taken all doses
\end{abstract}

Bangladesh Journal of Nutrition. Vol. 24-25 December, 2011-2012. Institute of Nutrition and Food Science, University of Dhaka, Dhaka-1000, Bangladesh.

* Author for Correspondence 
as a result there immunity was lesser than well-nourished children. Most of the caregivers of well-nourished children (43.5\%) knows that diarrhea causes by not giving immunization, on the other hand majority of caregiver of malnourished patients (31.9\%) knows that main cause of diarrhea is infection by germs. The immunization status of well nourished children was quite satisfactory. $62 \%$ well nourished children and only 40\% Mal nourished children was completely immunized. It has been seen that, ORS intake was higher in well-nourished children (172.2lml-on the $1^{\text {st }}$ day of hospitalization, compare to malnourished children. Stool output was higher in malnourished children $235.48 \mathrm{ml}$-on the $1^{\text {st }}$ day after admission. It shows that there is a co-relation between ORS intake, stool output and recovery period. It has been seen that, mean duration of diarrhea before hospitalization was lower in well-nourished children group, but duration of fever, vomiting and abdominal pain rate was higher in this group compared to malnourished group.

Key words: Hospital stay, Diarrhea, Malnut rition, Body weight.

\section{Introduction:}

With a population of more than 144 million, every day 700 Children die in malnutrition. One of the major causes for hospitalization in a general hospital is again diarrhea $(7.1 \%)^{1}$ Diarrhea is considered as the commonest and most important single health problem in developing countries, like Bangladesh, due to poor quality drinking water and malnutrition. In most cases, death is caused by dehydration $^{2}$ medically, dehydration is a serious and potentially life-threatening condition in which the body contains an insufficient volume of water for normal functioning. Based on the results of prospective studies conducted in the developing countries, it was estimated that about 500 million children under the age of 5 years develop diarrhea and 2-3 million of them die annually in Asia. ${ }^{3}$ Factors affecting nutritional status of children are not only food availability and accessibility or health services availability but also perhaps most importantly gender disparity, behavioural patterns of the caregivers and caring practices at household level. ${ }^{4}$ Malnuthtion has a significant effect not only on the individual member's welfare but also on the Bangladesh economy. ${ }^{15}$ Each year approximately 1 billion episodes of diarrhea are estimated to occur in developing countries and these episodes result in 3-4 millions of death each year ${ }^{5}$. In Bangladesh about $30 \%$ of death in children occurs due to diarrhea ${ }^{6}$. 


\section{Methodology:}

Study design: This was a cross sectional study involving under-five children admitted to the longer stay wards (LSU) of the hospital of ICDDR,B.

Study population: The study was conducted among 94 children of 6-59 months, of whom 49 were malnourished and 49 were wellnourished.64of them were male and 35 were female.

The questionnaire: Data were collected through interview of the mothers/attendants of the children, relevant clinical and laboratory information of the study children were collected from hospital records, and mothers/caregivers' perceptions of diarrhea and their severity was assessed through focus group discussion.

Data were analyzed in SPSS windows according to the objectives of the study.

\section{Anthropometric measurements:}

Anthropometric Measurements was measured by weight (kg), height (meter) and age (months) for assessing nutritional status and Z-scores was calculated and compared to the WHO standard. Normal nourishment is defined as no stunting, wasting or underweight (Z-score $>-1 \mathrm{SD})$.

\section{Results:}

A total of 94 children were included in the study. This chapter provides information on some of the socio-demographic characteristics and child health characteristics.

Table-I: Nutritional indication of the child.

\begin{tabular}{|l|c|c|c|}
\hline \multicolumn{1}{|c|}{ Factors } & $\begin{array}{c}\text { Well-nourished } \\
(\mathbf{n}=\mathbf{4 7})\end{array}$ & $\begin{array}{c}\text { Malnourished } \\
(\mathbf{n}=\mathbf{4 7})\end{array}$ & P value* \\
\hline $\begin{array}{l}\text { Age (month) } \\
\text { Mean(range) }\end{array}$ & $9(1-42)$ & $10(1-54)$ & 0.000 \\
\hline $\begin{array}{l}\text { Weight of the } \\
\text { (kg)children } \\
\text { (Mean+SD) }\end{array}$ & $7.57 \& 2.98$ & $5.68 \pm 2.02$ & 0.046 \\
\hline $\begin{array}{l}\text { Height of the children } \\
\text { (cm) } \\
\text { (Mean } \pm \text { SD) }\end{array}$ & $70.23 \pm 12.81$ & $65.2 \pm 10.4$ & \\
\hline *Frequencies & & \\
\hline
\end{tabular}


Bangladesh J. Nutr. Vol. 24-25 Dec 2011-2012

Table-2: Distribution by Age (In months) according to their nutritional status.

\begin{tabular}{|c|c|c|c|}
\hline $\begin{array}{c}\text { Age of the child } \\
\text { (In months) }\end{array}$ & $\begin{array}{c}\text { well-nourished } \\
(\mathbf{n}=\mathbf{4 7})\end{array}$ & $\begin{array}{c}\text { Malnourished } \\
(\mathbf{n}=\mathbf{4 7})\end{array}$ & Total* \\
\hline $6-12$ & 27 & 25 & 52 \\
\hline $13-19$ & 6 & 8 & 14 \\
\hline $20-26$ & 6 & 5 & 1 \\
\hline $27-33$ & & 1 & 4 \\
\hline $34-40$ & 3 & 1 & 9 \\
\hline $41-47$ & 4 & 5 & 1 \\
\hline$>47$ & 1 & & \\
\hline
\end{tabular}

Table-3: Distribution of the gender of the child.

\begin{tabular}{|c|c|c|c|}
\hline Gender of the child & $\begin{array}{c}\text { Well-nourished n } \\
\mathbf{( \% )} \\
(\mathbf{n}=\mathbf{4 7})\end{array}$ & $\begin{array}{c}\text { Malnourished n } \\
\mathbf{( \% )} \\
(\mathbf{n}=\mathbf{4 7})\end{array}$ & P-value* \\
\hline Male & $33(35.1)$ & $28(30.1)$ & \multirow{2}{*}{0.280} \\
\hline Female & $14(14.9)$ & $19(20.2)$ & \\
\hline * Cross tabulation count
\end{tabular}

Table-4: Distribution of the caregiver's.

\begin{tabular}{|c|c|c|c|}
\hline $\begin{array}{c}\text { Relationship of the } \\
\text { caregiver }\end{array}$ & $\begin{array}{c}\text { Well-nourished } \\
\mathbf{n}(\%)\end{array}$ & $\begin{array}{c}\text { Malnourished } \\
\mathbf{n}(\mathbf{\%})\end{array}$ & P-value* \\
\hline Mother & $45(95.7)$ & $42(89.4)$ & \multirow{2}{*}{0.218} \\
\hline Father & $2(4.3)$ & $1(2.1)$ & \\
\hline Grandmother & 0 & $2(4.3)$ & \\
\hline Sister & 0 & $2(4.3)$ & \\
\hline * Cross tabulation count & \\
\hline
\end{tabular}


Rahman and Islam : Nutritional Status and Food Security

Table-5: Distribution by Immunization status (\%).

\begin{tabular}{|c|c|c|c|}
\hline Number of Vaccine Doses & $\begin{array}{c}\text { Well-nourished } \\
\mathbf{( \% )}\end{array}$ & $\begin{array}{c}\text { Malnourished } \\
\text { (\%) }\end{array}$ & P-value* \\
\hline All doses & 62 & 40 & \multirow{2}{*}{0.218} \\
\cline { 1 - 3 } Not all doses & 39 & 49 & \\
\hline Not at all & 0 & 12 & \\
\hline * Pearson Chi-square test & \multicolumn{2}{|l}{} \\
\hline
\end{tabular}

Table-6: Distribution of the time of giving complementary food.

\begin{tabular}{|c|c|c|c|}
\hline $\begin{array}{l}\text { Time of giving } \\
\text { complementary food }\end{array}$ & $\begin{array}{l}\text { Well-nourished } \\
(n=47) \text { n (\%) }\end{array}$ & $\begin{array}{l}\text { Malnourished } \\
(n=47) \text { n (\%) }\end{array}$ & P-value* \\
\hline$<2$ months & $14(31.8)$ & $29(64.4)$ & \multirow{3}{*}{0.000} \\
\hline 3-5 months & 12(27.3) & 14(31.1) & \\
\hline 6-9 months & 18(40.9) & $2(4.4)$ & \\
\hline
\end{tabular}

Table-7: Distribution of Source of Drinking Water.

\begin{tabular}{|c|c|c|c|}
\hline Factors & $\begin{array}{l}\text { Well-nourished } \\
(\mathrm{n}=47) \text { n (\%) }\end{array}$ & $\begin{array}{l}\text { Malnourished } \\
(n=47) \text { n (\%) }\end{array}$ & P-value* \\
\hline Tube well & $20(42.6)$ & $24(51.1)$ & \multirow{4}{*}{0.001} \\
\hline Supply water & $10(21.3)$ & $14(44.7)$ & \\
\hline $\begin{array}{c}\text { Supplied water after } \\
\text { purified }\end{array}$ & $16(34)$ & $2(4.3)$ & \\
\hline Other & $1(2.1)$ & 0 & \\
\hline
\end{tabular}


Bangladesh J. Nutr. Vol. 24-25 Dec 2011-2012

Table-8: Distribution of hand Wash Practices.

\begin{tabular}{|c|c|c|c|}
\hline Factors & $\begin{array}{c}\text { Well-nourished } \\
(\mathbf{n = 4 7 )} \mathbf{n}(\mathbf{\%})\end{array}$ & $\begin{array}{c}\text { Malnourished } \\
(\mathbf{n = 4 7 )} \mathbf{n}(\mathbf{\%})\end{array}$ & \\
\hline Always & $44(93.6)$ & 25(53.2) & \multirow{2}{*}{0.000} \\
\hline Very often & $1(2.1)$ & $9(19.1)$ & \\
\hline Not usually & $2(4.3)$ & $13(27.7)$ & \\
\hline * Cross tabulation count & & \\
\hline
\end{tabular}

Table-9: Distribution of Practice of feeding colostrums.

\begin{tabular}{|c|c|c|c|}
\hline Factors & $\begin{array}{c}\text { Well-nourished } \\
(\mathbf{n = 4 7 )} \mathbf{n}(\mathbf{\%})\end{array}$ & $\begin{array}{c}\text { Malnourished } \\
\mathbf{( n = 4 7 ) ~ n ~ ( \% ) ~}\end{array}$ & \\
\hline Yes & $38(80.9)$ & $3(6.4)$ & \multirow{2}{*}{0.000} \\
\hline No & $9(19.1)$ & $44(93.6)$ & \\
\hline * Cross tabulation count & & \\
\hline
\end{tabular}

Table-10: Distribution of the type of food beside breast milk.

\begin{tabular}{|c|c|c|c|}
\hline $\begin{array}{c}\text { Type of food beside } \\
\text { breast milk }\end{array}$ & $\begin{array}{c}\text { Well-nourished } \\
\text { n (\%) }\end{array}$ & $\begin{array}{c}\text { Malnourished } \\
\text { n (\%) }\end{array}$ & \multirow{2}{*}{ P-value* $^{*}$} \\
\cline { 1 - 3 } Animal milk & $9(19.1)$ & $18(38.3)$ & \multirow{2}{*}{0.029} \\
\hline Tin milk & $20(42.6)$ & $16(34.0)$ & \\
\hline Water & $7(14.9)$ & $4(8.5)$ & \\
\cline { 1 - 3 } Family food & $4(8.5)$ & $1(2.1)$ & \\
\hline Suji & $6(12.8)$ & $1(2.1)$ & \\
\cline { 1 - 2 } Not applicable & 0 & $7(10.1)$ & \\
\hline * Cross tabulation count & & \\
\hline
\end{tabular}


Table-11: Comparison of Recovery day after admission of children with different nutritional status.

\begin{tabular}{|l|c|c|c|}
\hline Nutritional of the child & $\begin{array}{c}\text { Well-nourished } \\
(\mathbf{n}=\mathbf{4 7})\end{array}$ & $\begin{array}{c}\text { Malnourished } \\
(\mathbf{n}=\mathbf{4 7})\end{array}$ & P-value* \\
\hline Recovery day (Mean \pm SD) & $3.66 \pm 10.1$ & $5.21 \pm 1.71$ & 0.000 \\
\hline * Student $t$ test & \\
\hline
\end{tabular}

Mean age of the well-nourished children was lower than malnourished child (Table-l). Most of the patients at the hospital were between 6 and 12 months. There were 27\% Well nourished and 25\% malnourished child ( $>2$ wt-for-age). So children over 12 months ( 1 year) were mote immune to diarrhea than children under 12 months of age (Table-2). It has been seen that about one third of the well-nourished children (35.1\%) and majority of malnourished children (30.1\%) were boys (Table-3). Table-4 shows that the percentage of mother as a primary caretaker was high $(95.7 \%)$ than the percentage of malnourished children (89.4\%). When mother was working outside or was absent for a long time, the caretaker looks after the child. In $4.3 \%$ cases of malnourished children's, grandmother takes care of the child when mother was away. On the other hand all the well-nourished children are taken care by parents. It has been seen that, the majority of well nourished children (62\%) were immunized by taking all doses of Vaccines, where us, most of the malnourished children (49\%) has not taken all doses as a result there immunity was lesser than well-nourished children. The immunization status of well nourished children was quite satisfactory. $62 \%$ well nourished children and only 40\% Mat nourished children was completely immunized (Table-5). It has been seen that, the majority of well nourished children $40.9 \%$ were given complimentary food at the age of $6-9$, on the other hand $64.4 \%$ malnourished children was given earlier (Table-6). As a source of drinking water about $51.1 \%$ malnourished family used tube water, $42.6 \%$ well-nourished family used tube well water (Table-7). Most of the people having well-nourished children (93.6\%) used to wash their hand always .On the other hand, only 53.2\% people having a malnourished children used to wash their hand always (Table-8). Table-9 depicts that, Most of the parents of well-nourished children used to feed colostrums (80.6\%) but Parents having malnourished children don't have practice enough to feed colostrums to their child (93.6\%). Most of the mothers having well-nourished children used to feed tin milk (42.6\%) on the other hand most of the mother having malnourished children (38.3\%) used to give animal milk beside breast milk (Table-10). It has been seen in (Table-11) that, recovery day was lower in well-nourished group (3.66) on the other hand, malnourished children's mean recovery time was much higher than well-nourished group. It reveals that, a well nourished child recovers quickly than malnourished children $(\mathrm{p}<0.000)$.

\section{Discussion:}

The study presents the relationship between nutritional status and recovery period during hospitalization in the hospital. it was a hospital based cross sectional study conducted on 94 children of 6-59 months, of whom 49 were malnourished and 49 were 
well nourished 64 of them were male and 35 were female. It means that boy's are more sufferers in diarrhea than girls. Children's age come within a range of 6-59 months. Mother's education level was lower, 32.6\% mothers were illiterate and $40 \%$ mothers of malnourished children were illiterate where, $25 \%$ mothers having well nourished child were illiterate. It means that, children having illiterate mother are suffering malnutrition than of literate. Whereas 25 fathers were illiterate. Though mothers take care of the child and their educational level are so poor, so they can't take proper care of the child. For this' most of the children suffers from various infectious diseases. Most of the malnourished children's Family income was below TK. 5,000 per month for majority of the parents whereas, most of the well nourished children's family income was 8,000tk. It shows that, children having low family income are more likely malnourished than well nourished children. Family member was within 4 persons for majority of the well nourished children's households'. On the other hand family member was more than 5 in most of the malnourished households. Within their limited income; it was difficult to maintain medium size family properly.

As has been reported in several nutritional surveys conducted in Bangladesh, malnutrition is one of the major health problems in Bangladesh, as elsewhere in the developing world. Children under 5 happen to be the most affected. Under 5 mortality rates are 89/1000 live births due to different causes including malnutrition. Our study reveals that knowledge, attitude and practices of dietary pattern, health, sanitation and immunization of the malnourished children's family were lower than well-nourished children's family. Their nutritional knowledge was too low, compared with well nourished children's parents.

Colostrums play an important role in immunization. It is rich in immunologic which can protect children from various infectious diseases. Due to rejection of Colostrums, immunity power of children lowers and children suffers from various infectious diseases. As a result children become malnourished. In our study, Most of the parents of well-nourished children used to feed colostrums (80.6\%) but Parents having malnourished children discarded colostrums (93.6\%).

Complementary feeding is most essential for the children after complete 6 months of age. In Child Nutrition Survey (BBS, 1991) revealed that, 30\% of children were introduction to solid food after 9 months and $80 \%$ children received rice-based food ${ }^{1}$. Our study reveals that $64.4 \%$ malnourished children's mother has started complementary food in $<2$ months of age, on the other hand majority of well-nourished children's mother gave their child complementary food at the age of 6-9 months. Delayed introduction of weaning food observed in our study that is similar to other studies of Bangladesh and lndia ${ }^{10}$. A survey in Dhaka slums by ICDDR, B shows that $18.7 \%$ of the $0-2$ month's old infant and more than half of the 3-5 months old infants were receiving semi solid food ${ }^{11}$. Early weaning is harmful because that decreases the infant's time at breast feeding, limiting the supply of breast milk and it is likely to be related with infection. Delayed introduction is also responsible for growth retardation. Because after 6 months of age, nutritional requirement of the children gradually increases with age but the supply of nutrition from mother's milk cannot fulfill the requirement. As a result the growth of children is lowered and they suffer from 
malnutrition. Another stud in United Arab Emirates (UAE) showed that $60 \%$ of children had received semisolid food within two months of life?

It has been seen that, the majority of well nourished children (62\%) were immunized by taking all doses of Vaccines. where as most of the malnourished children (49\%) has not taken all doses as a result there immunity was lesser than well-nourished children. Most of the caregivers of well-nourished children (43.5\%) knows that diarrhea causes by not giving immunization, on the other hand majority of caregiver of malnourished patients (31.9\%) knows that main cause of diarrhea is infection by germs. The immunization status of well nourished children was quite satisfactory. $62 \%$ well nourished children and only 40\% Mal nourished children was completely immunized. In Child Nutrition Survey ${ }^{62}$ (BBS, 1997) $76.7 \%$ were immunized. The rate of immunization was lower than BBS, 1997. In our study, only $42.2 \%$ were drinking safe water (Fig-9). Inappropriate source of drinking water is a risk factor for infectious diseases. It has been observed that $19.5 \%$ mothers of well-nourished children's has given EBF for first 6 months of the life, but less than that only 8.5\% mothers having malnourished children has given EBF to their child. It shows that practice of breast feeding yet not good enough in our society.

Our study reveals that, most of the parents of well-nourished children used to feed colostrums (80.6\%) but Parents having malnourished children don't have practice enough to feed colostrums to their child (93.6\%). Most of the mothers having wellnourished children used to feed tin milk (42.6\%) on the other hand most of the mother having malnourished children (38.3\%) used to give animal milk beside breast milk. 89.4\% mothers of well-nourished children and 83\% mothers of malnourished children know that the main symptom of diarrhea is the increased amount of stool. Most of the mothers, 83\% well-nourished and 56.5\% malnourished Mothers used to give less amount of food during diarrhea. Most of the well-nourished children received treatment before hospitalization (55.3\%) On the other hand most of the malnourished children (59.6\%) didn't receive any treatment before hospitalization. During diarrhea, $75 \%$ of the well-nourished children's were taken to qualified doctor, but on the other hand, most of the malnourished children's (59.6\%) were taken to pharmacist.

It has been seen that, ORS intake was higher in well-nourished children (172.21 ml-on the $1^{\text {st }}$ day of hospitalization, compare to malnourished children. Stool output was higher in malnourished children $235.48 \mathrm{ml}$-on the $1^{\text {st }}$ day after admission. It shows that there is a co-relation between ORS intake, stool output and recovery period.

In our study, (mean \pm SD) weight, height of the children were found (Table-1). In child Nutrition Survey ${ }^{7}$ the mean value of weight, height of the children were found respectively. Again in Nutrition Survey of Bangladesh ${ }^{10}$ the mean value of weight, height was also found. Mean anthropometrics values of present study are lower than the values reported in Child Nutrition Survey and Nutrition Survey of Bangladesh ${ }^{10}$.

During hospitalization, weight for age Z score was better in discharge among patients than admission. Weight for height $\mathrm{Z}$ score was also better in discharge than admission. Because when the children stay in home they can't get proper food, treatment and care. Beside this, their water and electrolyte balance also disturbed. So they loose their 
weight. But after admission in hospital they get proper diet rich in carbohydrate, protein, fat and micronutrient such as vitamin A, zinc.

Stool output per kg Body weight positively correlated significantly with duration of hospitalization.

This finding is in agreement with the previous studies in Bangladesh, which, also have shown that malnutrition is highly prevalent amongst children during first 2-3 years of life ${ }^{10,11}$. Ethiopia, it was found that a high prevalence of stunting $(24.5 \%)$ and wasting (18.4\%) amongst pro-school children. Further more, more than $53 \%$ of the children were found to be malnourished. Relatively higher proportion of wasting was recorded in children below the age of three years, while the rate of stunting increased as age increased.

Our study showed that recovery day was lower in well-nourished group (3.66) on the other hand, malnourished children's mean recovery time was much higher than wellnourished group. It reveals that, a well-nourished child recovers quickly than malnourished children. $(\mathrm{p}<0.000)$

\section{References:}

1. Bryce J., Boschi-Pinto C., Shibuya K., Black E.R., the WHO Child Health Epidemiology Reference Group. WHO estimates of causes of death in children. Lancet 2005 March: 365 1147-1152

2. Sherwood L. Gorbach, Infection Diarrhoea, Black well scientific publications, 287.

3. Selim Ahmed, K K Talukder, Knowledge, attitude, and practice of Environment sanitation and personal hygiene of the school children in Rural Bangladesh, Institute of child and mother health, 2002, 39.

4. Barua Shampa. Sakiullah MD, The experiences of save the children's nutrition and child development program in rural villages in Bangladesh, Bangladesh Nutrition Conference, 2002, 41.

5. http://www.nlm.nih.gov/medlineplus/ency/article/001604.htm (accessed on April 10, 2006)

6. Shikder H. Profile of physical growth of different types of diarrhea diseases and pneumonia in a diarrhea hospital during hospitalization. 2004.

7. Donnen P.D., Brasseur M., Dramaix F., Vertongen B.N., Zihindala M. and Hennart P.; Vitamin A deficiency and protein energy malnutrition in a sample of pre-school age children in the Kivu Province in Zaire. Eur. J. Clin. Nutr., 1996, 50:456-461.

8. Bangladesh National Nutrition Survey, 1995-96, Institute of Nutrition and Food Science, University of Dhaka, July 1988.

9. Talukdar, M. Q. K., Kabir, A.R.M.L., Kawser, C.A.; Feeding pattern, sociodynamics, clinical spectrum and recovery of severely malnourished children: a study of 155 cases a study of 155 cases. Bangl. J. Child Health, 1988, 12: 14-21.

10. Khanum S.; Factor contributing to protein energy malnutrition in urban Dhaka. Bangl. J. Child. Health, 1985, 9:80-81.

11. Shakur S., Banu N., Ehsan MA.; Clinical, biochemical and socio-economic factors associated with severe degree of malnutrition in Children admitted in Dhaka Shisu Hospital, J. Dhaka, 1991, 7:5-12. 